\title{
Behaviour of laminated circular glass plates
}

\author{
M. Z. Aşık*
}

(Received 8 August 2003, revised February 11, 2004)

\begin{abstract}
Laminated circular glass plates consist of two or more thin glass plates and an interlayer PVB (PolyVinyl Butyral), and are widely used geometric types in modern structures. They can easily undergo large displacements since they are very thin. Their behaviour under large displacements has shown a highly nonlinear characteristic. The mathematical model needs to be developed to simulate this behaviour. The energy integral functional is written for the whole unit, and variations are taken with respect to lateral displacement and radial displacement to obtain the governing differential equations. Then, the nonlinear coupled differential equations are converted to the system of nonlinear algebraic equations by the use of finite difference approach.
\end{abstract}

${ }^{*}$ Department of Engineering Sciences, Middle East Technical University, Ankara, TÜRKIYE (TURKEY). mailto:azulfu@metu.edu.tr

See http://anziamj.austms.org.au/V45/CTAC2003/Asik for this article, (c) Austral. Mathematical Soc. 2004. Published June 3, 2004. ISSN 1446-8735 


\section{Contents}

1 Introduction

C339

2 Mathematical model

C340

$3 \quad$ Numerical results

C343

4 Conclusions

C346

References

C349

\section{Introduction}

Use of laminated glasses in modern structures is rapidly increasing since an interlayer PVB (polyvinyl butyral) bonds glass plates together without shattering away. As a result, the architects could meet codes for safety and security to prevent injuries to people. Besides that, the harmful effects of UV rays are also mitigated by the laminated units.

Laminated glass units which consist of two or more thin glass plates and an interlayer PVB could be in rectangular, circular or strip shapes. The unit can easily displace as much as about six times of the thickness of a glass plate since it is very thin compared to in-plane dimensions. Because of large displacements, its behaviour is nonlinear. Therefore, the equilibrium equations governing the behaviour of laminated glass units should be based on the large deflection theory in order to explain their true behaviour.

Vallabhan et al. [1] developed a mathematical model by using a variational approach to study the nonlinear behaviour of a laminated glass plate and conducted tests at the Glass Research and Testing Laboratory at Texas Tech University to verify the model. Recently, Vallabhan et al. [2], Aşık et al. [3] 
and Aşık [4] made contributions by their research on the true behaviour of glass units.

In the present study, laminated circular glass plates are considered to make known their behaviour to the design engineers. For this purpose, a mathematical model is developed to represent the true behaviour of laminated circular glass units. Variational principles are used in modelling the laminated glass unit. At first, the energy integral functional is written for the whole unit and variations are taken with respect to lateral displacement $w$ and radial displacements $u_{1}$ and $u_{2}$ to obtain the governing differential equations. Then, the three nonlinear coupled differential equations are converted to a system of nonlinear algebraic equations by use of the finite difference approach. The successive over relaxation method is used in the iterative solution procedure.

\section{Mathematical model}

A laminated circular glass unit is shown in Figure 1. The energy functional or the total potential energy in the unit is

$$
\Pi=U_{m}^{1}+U_{b}^{1}+U_{m}^{2}+U_{b}^{2}+U_{I}+V ;
$$

where $U_{m}^{1}$ and $U_{b}^{1}$ are the membrane and the bending strain energies for the glass plate at top, respectively; $U_{m}^{2}$ and $U_{b}^{2}$ are the membrane and the bending strain energies for the glass plate at bottom, respectively; $U_{I}$ is the shear strain energy in the interlayer; and $V$ is the potential energy function due to applied loads.

Then the integral functional is written in terms of the vertical displacement $w$, and in-plane displacements $u_{1}$ and $u_{2}$. To minimize the integral functional, variations are taken with respect to the vertical displacement $w$, and in-plane displacements $u_{1}$ and $u_{2}$. Therefore the three nonlinear coupled 


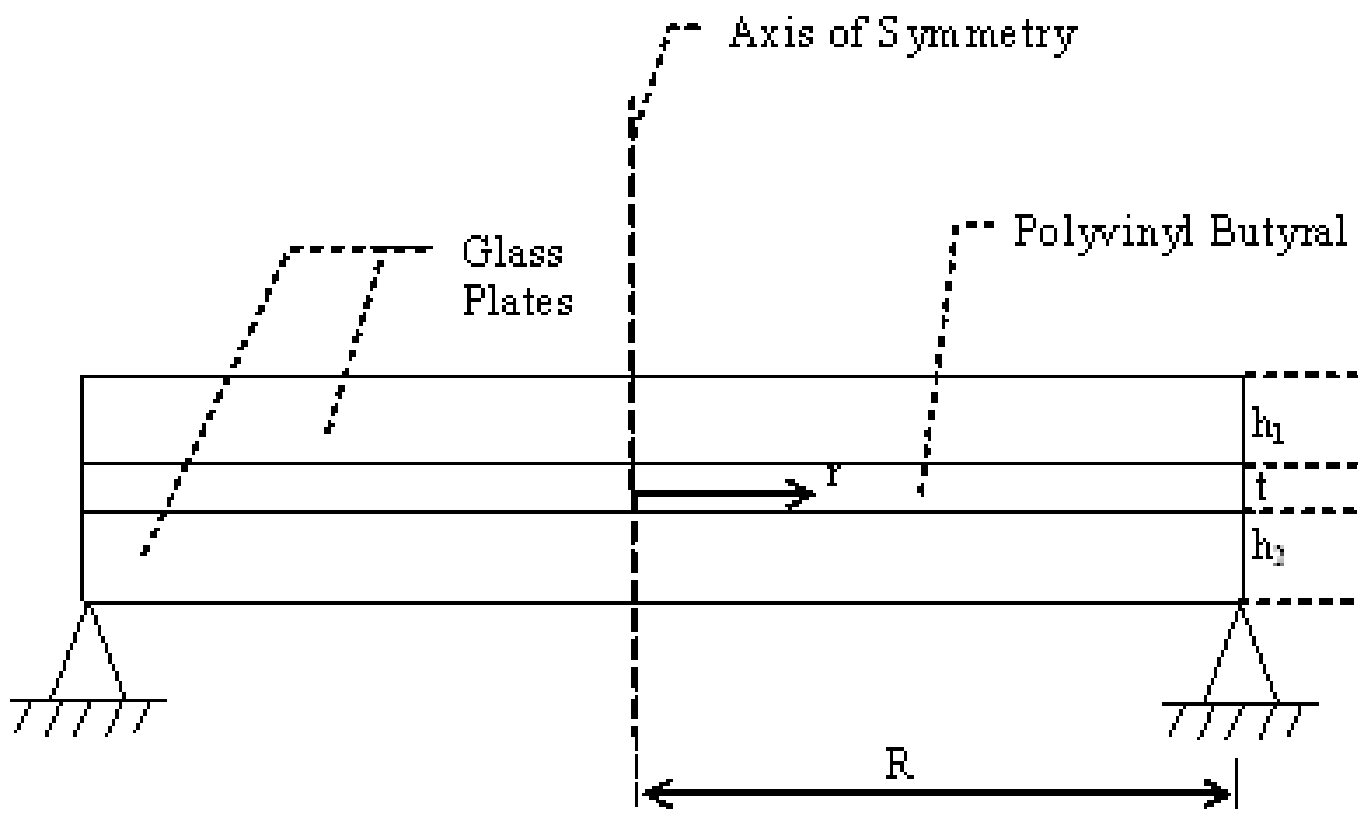

Figure 1: Laminated circular glass unit with an interlayer PVB 
differential equations and the boundary equations for a laminated circular glass unit are obtained:

$$
\begin{aligned}
& D \nabla^{4} w+\frac{G_{I}}{t}\left(t+\frac{h_{1}+h_{2}}{2}\right)^{2}=q \\
&+ \frac{E h_{1}}{1-\nu^{2}}\left\{\left[\frac{d u_{1}}{d r}+\frac{1}{2}\left(\frac{d w}{d r}\right)^{2}+\nu \frac{u_{1}}{r}\right] \frac{d^{2} w}{d r^{2}}\right. \\
&+ {\left.\left[\nu\left(\frac{d u_{1}}{d r}+\frac{1}{2}\left(\frac{d w}{d r}\right)^{2}\right)+\frac{u_{1}}{r}\right] \frac{1}{r} \frac{d w}{d r}\right\} } \\
&+ \frac{E h_{2}}{1-\nu^{2}}\left\{\left[\frac{d u_{2}}{d r}+\frac{1}{2}\left(\frac{d w}{d r}\right)^{2}+\nu \frac{u_{2}}{r}\right] \frac{d^{2} w}{d r^{2}}\right. \\
&+ {\left.\left[\nu\left(\frac{d u_{2}}{d r}+\frac{1}{2}\left(\frac{d w}{d r}\right)^{2}\right)+\frac{u_{2}}{r}\right] \frac{1}{r} \frac{d w}{d r}\right\} } \\
&- \frac{G_{I}}{t}\left(t+\frac{h_{1}+h_{2}}{2}\right)\left[\frac{u_{1}-u_{2}}{r}+\frac{d u_{1}}{d r}-\frac{d u_{2}}{d r}\right] \\
& \frac{E h_{1}}{1-\nu^{2}}\left[\frac{d^{2} u_{1}}{d r^{2}}+\frac{1}{r} \frac{d u_{1}}{d r}-\frac{u_{1}}{r^{2}}\right]=-\frac{E h_{1}}{1-\nu^{2}}\left[\frac{d w}{d r} \frac{d^{2} w}{d r^{2}}+\frac{1-\nu}{2 r}\left(\frac{d w}{d r}\right)^{2}\right] \\
&+\frac{G_{I}}{t}\left[u_{1}-u_{2}-\left(\frac{h_{1}+h_{2}}{2}+t\right) \frac{d w}{d r}\right]
\end{aligned}
$$

$\frac{E h_{2}}{1-\nu^{2}}\left[\frac{d^{2} u_{2}}{d r^{2}}+\frac{1}{r} \frac{d u_{2}}{d r}-\frac{u_{2}}{r^{2}}\right]=-\frac{E h_{2}}{1-\nu^{2}}\left[\frac{d w}{d r} \frac{d^{2} w}{d r^{2}}+\frac{1-\nu}{2 r}\left(\frac{d w}{d r}\right)^{2}\right]$$$
-\frac{G_{I}}{t}\left[u_{1}-u_{2}-\left(\frac{h_{1}+h_{2}}{2}+t\right) \frac{d w}{d r}\right]
$$

$D=D_{1}+D_{2}$ in which $D_{1}=E h_{1}^{3} /\left[12\left(1-\nu^{2}\right)\right], D_{2}=E h_{2}^{3} /\left[12\left(1-\nu^{2}\right)\right]$; $h_{1}$ and $h_{2}$ are the thicknesses of the top and bottom glasses, respectively; $t$ is the thickness of interlayer; $G_{I}$ is the shear modulus of the interlayer; $E$ is the modulus of elasticity of the glass beams; $\nu$ is Poisson's ratio; and $q$ is a uniformly distributed load. 
The boundary conditions for a simply supported circular plate are:

- at $r=0, u_{1}=0, u_{2}=0, \frac{d w}{d r}=0$; and

- at $r=R$

$$
\begin{aligned}
& -N_{1 r}=0\left(\text { that is, } \frac{d u_{1}}{d r}+\frac{1}{2}\left(\frac{d w}{d r}\right)^{2}+\nu \frac{u_{1}}{r}=0\right), \\
& -N_{2 r}=0\left(\text { that is, } \frac{d u_{2}}{d r}+\frac{1}{2}\left(\frac{d w}{d r}\right)^{2}+\nu \frac{u_{2}}{r}=0\right), \\
& -w=0, M_{r}=0\left(\text { that is, } \frac{d^{2} w}{d r^{2}}+\frac{\nu}{r} \frac{d w}{d r}=0\right) .
\end{aligned}
$$

\section{$3 \quad$ Numerical results}

Equations (2-4) are transformed into the nonlinear system of algebraic equations by using finite difference procedure, and then they are solved by using the iterative procedure since they are nonlinear and coupled. The following data are used for the laminated glass unit in Figure 1: $R=1 \mathrm{~m}$; the thickness of each beam, $h_{1}=h_{2}=h=0.005 \mathrm{~m}$; modulus of elasticity of the glass, $E=64.5 \mathrm{GPa}$ for glass units; modulus of elasticity, $G_{I}=1000 \mathrm{kPa}$ and the thickness, $t=0.00038 \mathrm{~m}$ for the interlayer.

The applied load is uniformly distributed over top surface of the top glass plate. Pressure $q$ is applied in increments to have a converged solution.

The developed mathematical model is verified by considering a laminated simply supported beam as shown in Figure 2 [5] since the experimental results are available from tests conducted in the laboratory for the concentrated load at centre. Even if large deflection theory is used, linear behaviour is observed for a simply supported beam. The results obtained for a laminated simply supported beam fitted well as shown in Figure 2.

Figure 3 presents the comparison of the displacements obtained for a laminated circular glass unit by considering the nonlinear equations (2-4) 


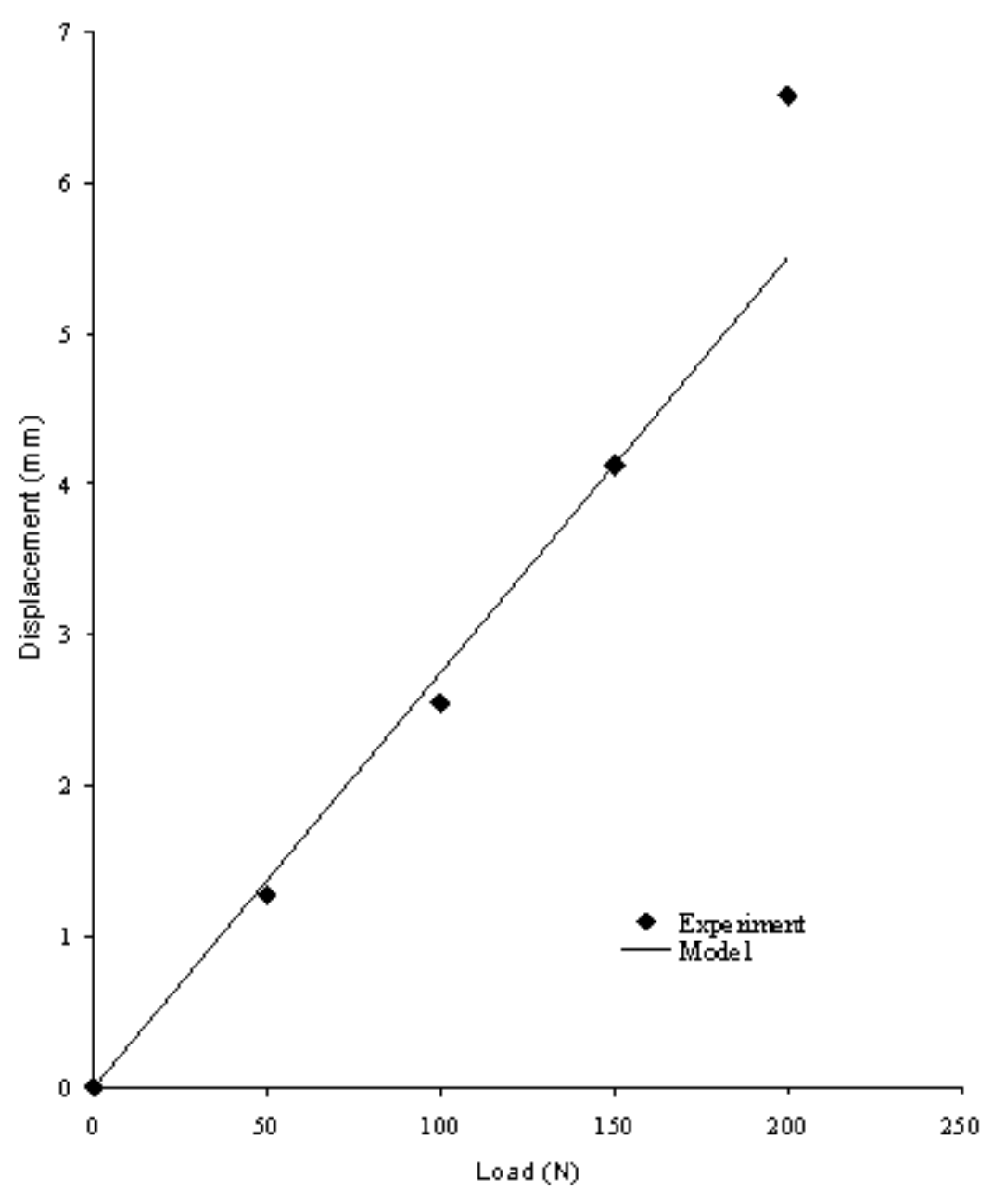

FiguRE 2: Maximum deflection versus load for simply supported beam (comparison with experimental results) 


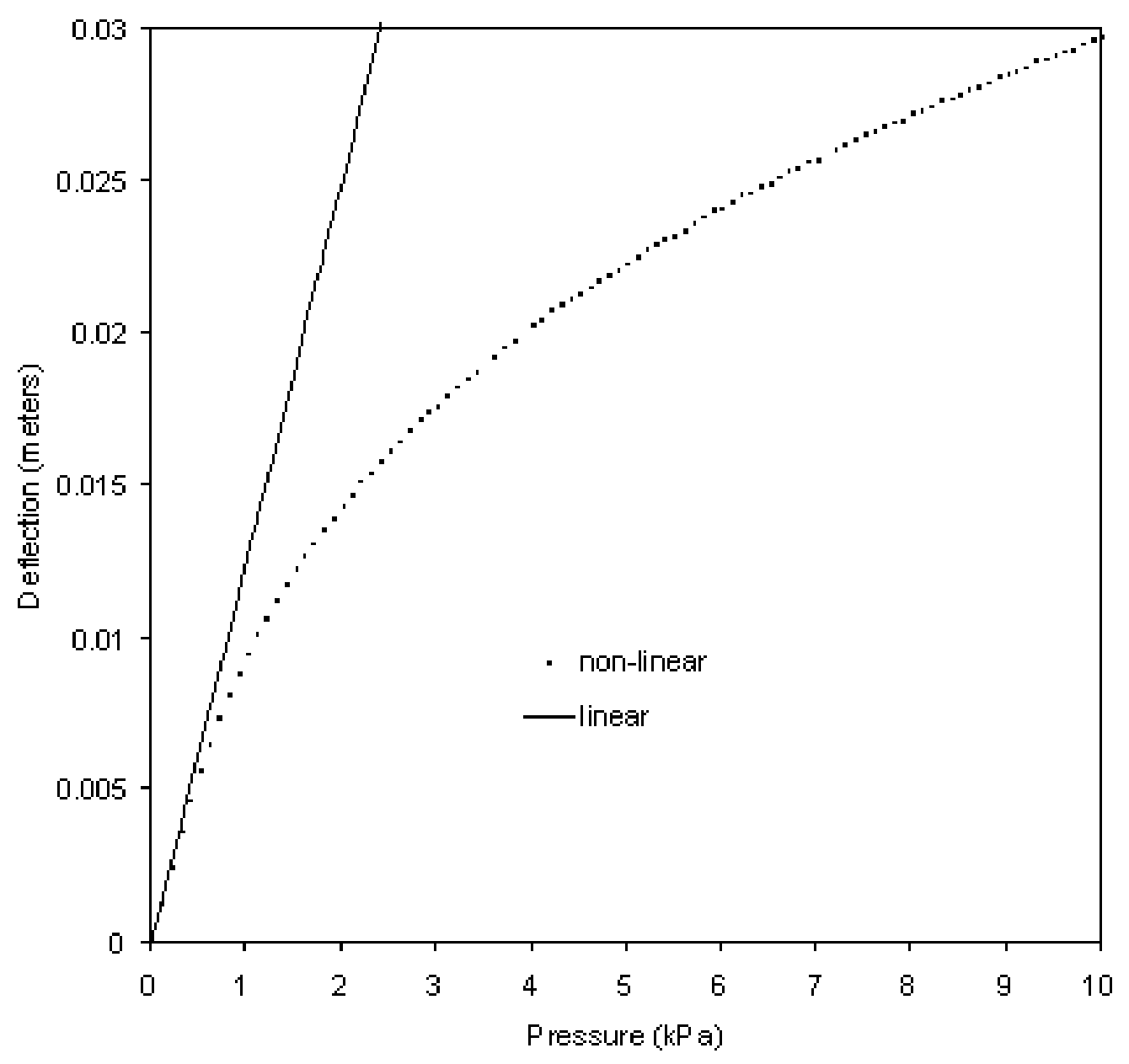

Figure 3: Maximum deflection at centre versus pressure 
with the displacements obtained from linear solution. Nonlinear behaviour due to the developing of membrane forces is easily observed.

Figure 4 is plotted to compare the displacements of layered glass plate having two glass layers without interlayer, laminated glass plate having two glass layers bonded together by Polyvinyl Butyral (PVB) and monolithic glass plate of single layer having a thickness equal to the total thickness of glass layers in laminated glass unit or layered glass unit. Radius $\mathrm{R}$ is taken as $0.5 \mathrm{~m}$ for all plates in Figure 4. The behaviour of the laminated plate is bounded by the behaviour of layered plate and monolithic plates as it is observed from this figure.

The stress distribution along the radius is given in Figure 5. Stress for small pressures is maximum at the centre. But maximum stress moves towards edges as pressure is increasing. This behaviour is typical when the nonlinear behaviour is considered instead of linear behaviour, because the membrane forces are developing as pressure is increasing. Developing membrane forces make the unit stiffer.

\section{Conclusions}

Laminated circular glass unit shows nonlinear behaviour under higher pressure values. It means that the nonlinear behaviour dominates when the effective membrane stresses develop. Nonlinear behaviour is the true behaviour for the thin laminated glass plates Therefore, it is important to consider the nonlinear strain tensor in the analysis of laminated circular plates.

Acknowledgments: The author acknowledges the support from BAP (Scientific Research Projects in Middle East Technical University), Grant AFP2003-03-10-01 for the research on laminated glasses. 


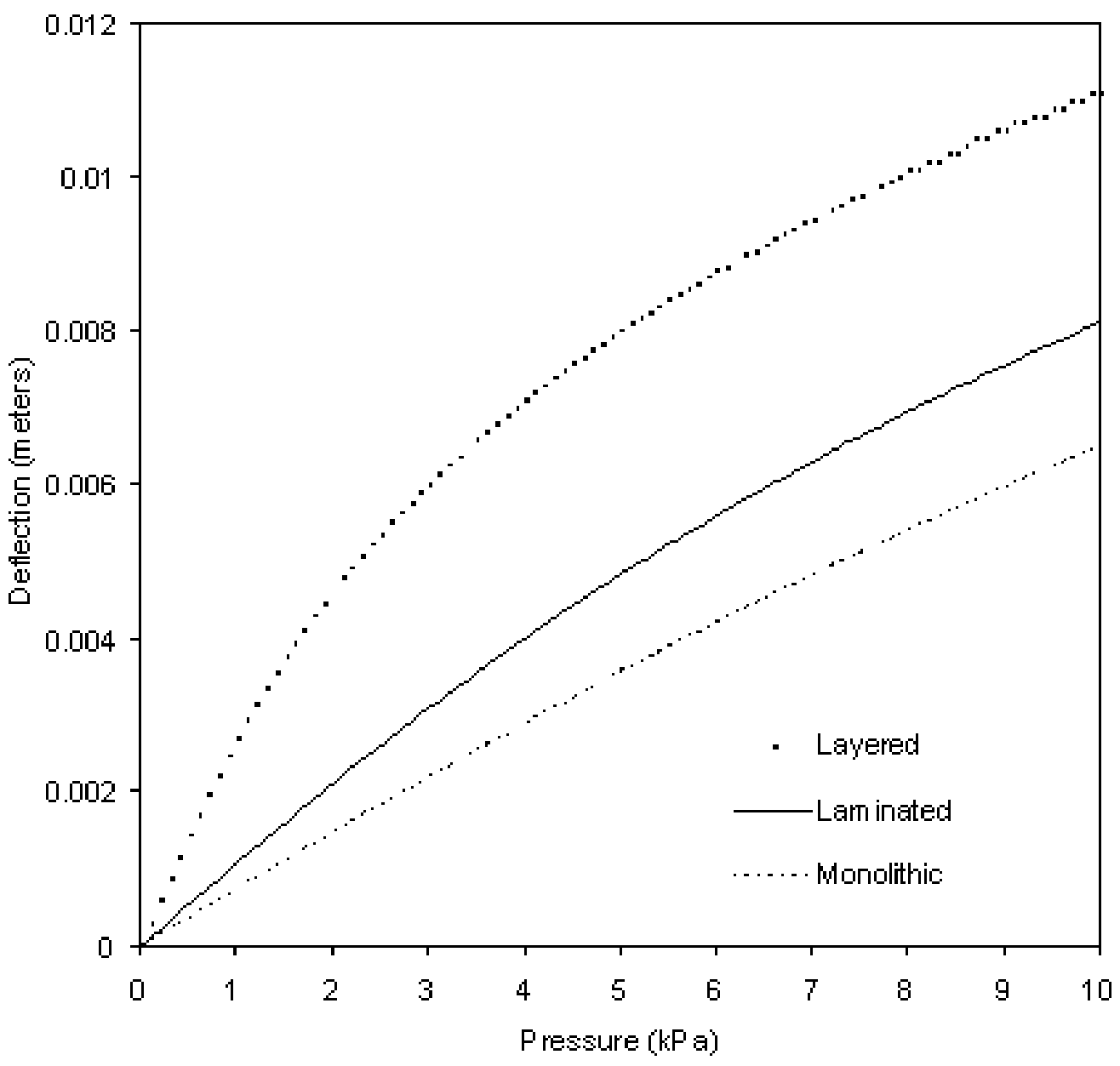

FiguRE 4: Maximum deflection at centre versus pressure (comparison) 
Radial Distance, $r$ (meters)

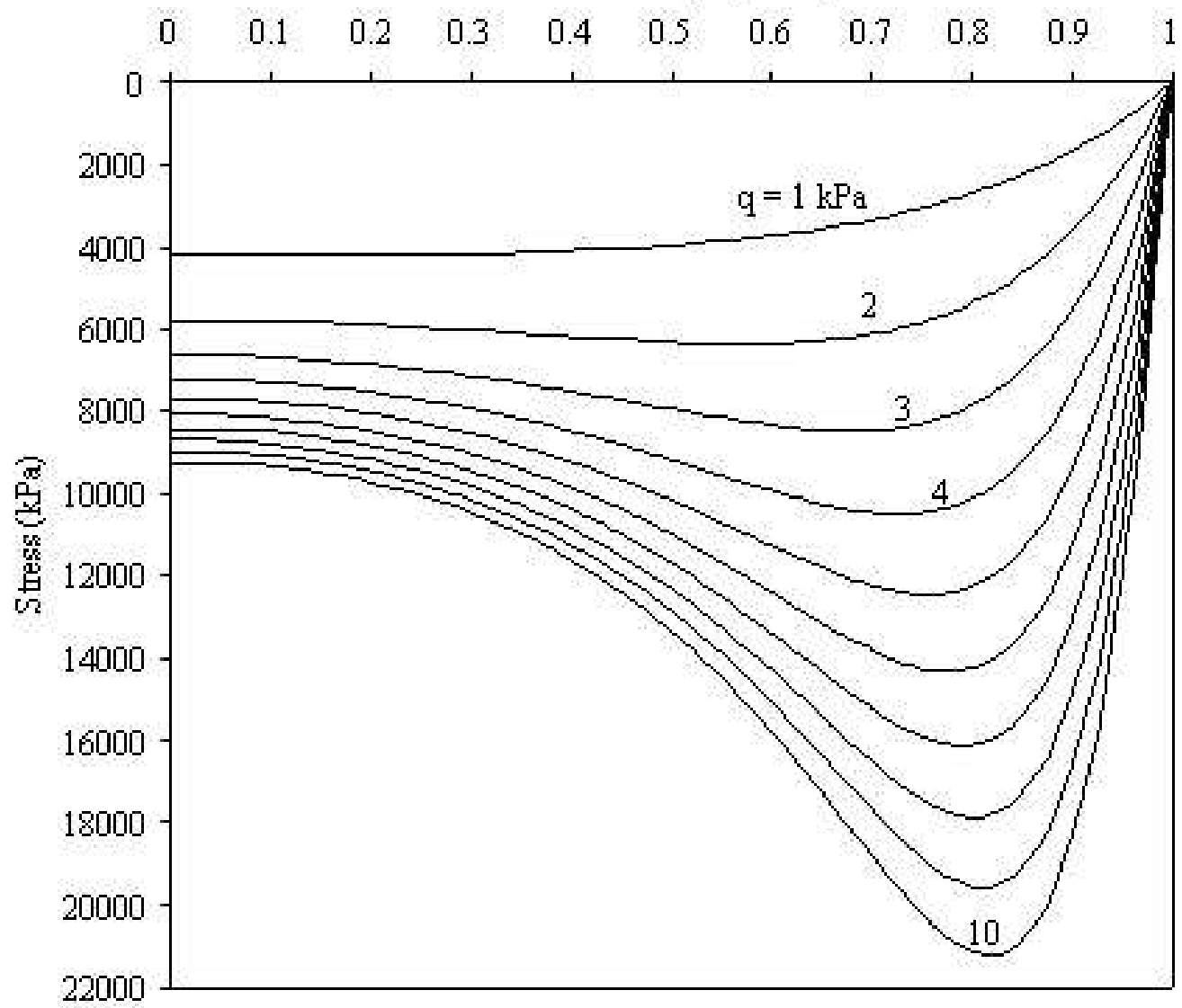

FIGURE 5: Radial stress at bottom of unit along radius 


\section{References}

[1] C. V. G. Vallabhan, Y. C. Das, M. Magdhi, M. Z. Aşık and J. B. Bailey. Analysis of Laminated Glass Units. J. of Struct. Engrg., ASCE, 119(5):C1572-C1585, 1993. C339

[2] C. V. G. Vallabhan, M. Z. Aşık, and K. Kandil. Analysis of Structurally Glazed Systems. J. of Computers \&5 Structures, 65(2):C231-C239, 1997. C339

[3] M. Z. Aşık and C. V. G. Vallabhan. On the Convergence of Nonlinear Plate Equations. J. of Computers \& Structures, 65(2):C225-C229, 1997. C339

[4] M. Z. Aşık. Laminated Glass Plates: Revealing of Nonlinear Behaviour. J. of Computers \& Structures, 81(28-29):C2659-C2671, 2003. C340

[5] M. Z. Aşık and Selim Tezcan. Effect of Support Conditions on the Behaviour of the Laminated Composite Beams. European Conference on Computational Mechanics, Cracow, Poland, June 26-29, 2001. C343 